\title{
A PLANT INDUSTRY BASED UPON MUTATION
}

\author{
Varieties of Egyptian Cotton Have Arisen Largely Through Mutation- \\ Possible Relation Between Mutation and Hybridity- \\ Many Problems Still Left For Solution \\ Thomas H. Kearney
}

Physiologist in Charge, Alkali and Drought-Resistant Plant Investigations,
Bureau of Plant Industry, U. S. Department of Agriculture

M

OST species of crop plants comprise numerous well-marked varieties. How these have originated in the seed-propagated crops is still, in large measure, an unsolved problem. In some cases, however, the evidence points to origin by mutation, a phenomenon analogous to bud-sporting, in fruit trees and other vegetatively propagated plants. Mutation manifests itself in the sudden appearance of an individual which differs from the parent stock in one or more strongly heritable characters. If this individual "breeds true," the new characters being uniformly expressed in its progeny generation after generation, a stable new variety will have been produced.

\section{MUTATION HARD TO EXPLAIN}

Certain geneticists have endeavored to explain mutation on the basis of Mendelian recombination. It must be admitted that in the familiar case of Oenothera, for example, the attempt has not been completely successful. Nor will this explanation cover the apparently well-authenticated examples of mutation in asexually propagated organisms. The possibility should be considered that mutation is not a simple but a complex phenomenon, which results from different causes in different groups of organisms. In Egyptian cotton, the group discussed in this paper, there is some evidence of a relation between mutation and hybridity, although simple recombination does not afford an adequate explanation of the facts.

\section{DESCRIPTION OF EGYPTIAN COTTON}

Before going further into this question, it may be in order to consider briefly the nature and uses of Egyptian cotton and to review the plant breeding work which has led to its commercial production in the United States.

Egyptian cotton differs from any other commercially grown cotton, although showing many points of similarity to the American Sea Island. The parentage of this type, which originated in Egypt about seventy-five years ago, is obscure. Some authorities believe it to have resulted from hybridization of Sea Island with a brown linted African tree cotton, both of which were grown in Egypt during the early part of the nineteenth century. ${ }^{1}$ However this may be, the type is now a well-defined one, and while it comprises several distinct varieties, all of these share certain peculiarities which distinguish them from other commonly cultivated cottons.

Commercially, Egyptian cotton is characterized by the superior strength and by the color of the fiber, the latter varying from light brown ${ }^{2}$ in some varieties to pale buff or nearly pure white in others.

The length of the fiber ranges, in the different varieties, from $1 \frac{1}{16}$ to $13 / 4$

${ }^{I}$ See Balls, W. L. The Cotton Plant in Egypt. London, 1912. The origin of the Egyptian type is discussed on pages 3 and 4 .

2 Balbriggan underwear was formerly manufactured only from the undyed fiber of brown Egyptian cotton. 


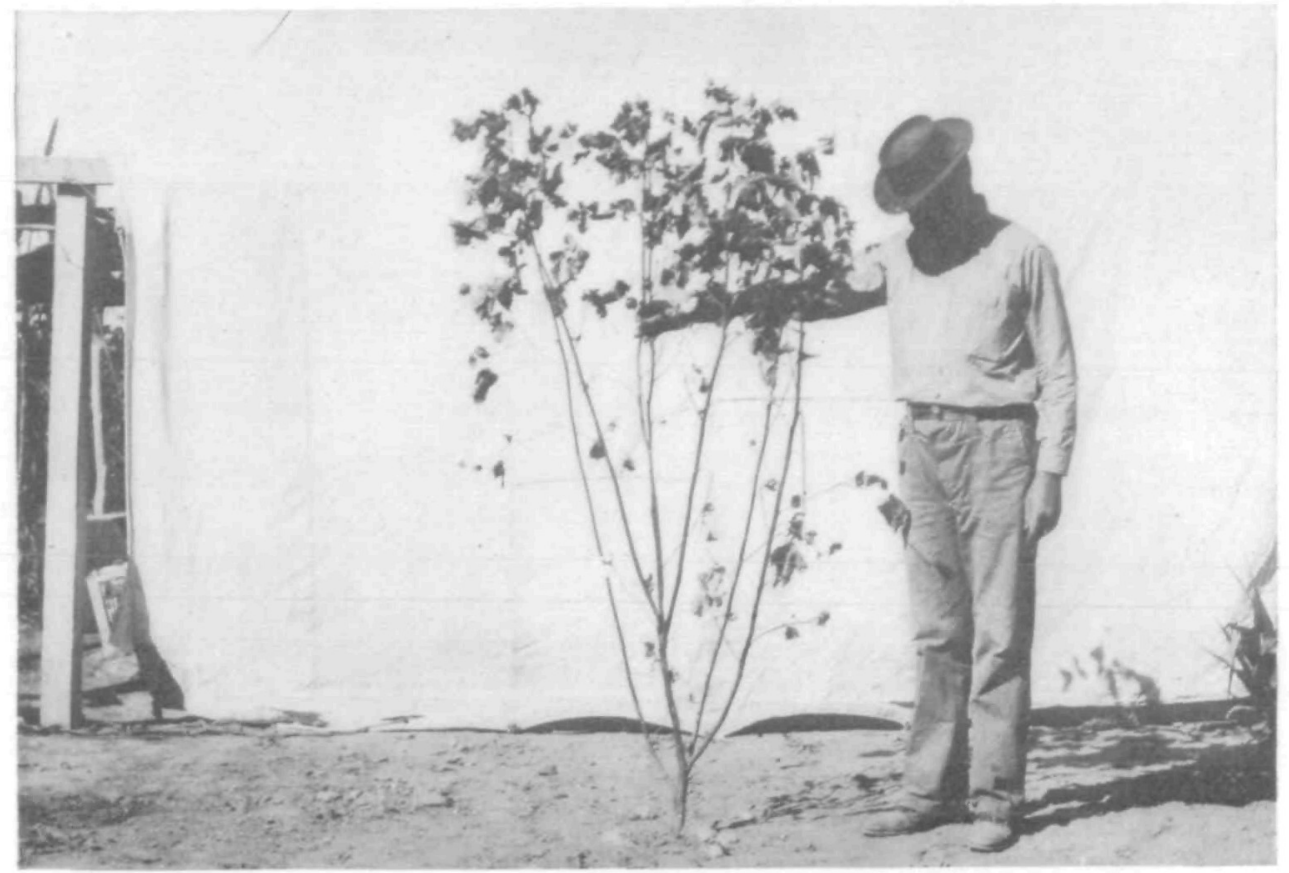

PLANT GROWN FROM NEWLY IMPORTED SEED

The plants grown in Arizona from newly imported seed of Egyptian cotton were unfruitful and late in maturing. (Fig. 1.)

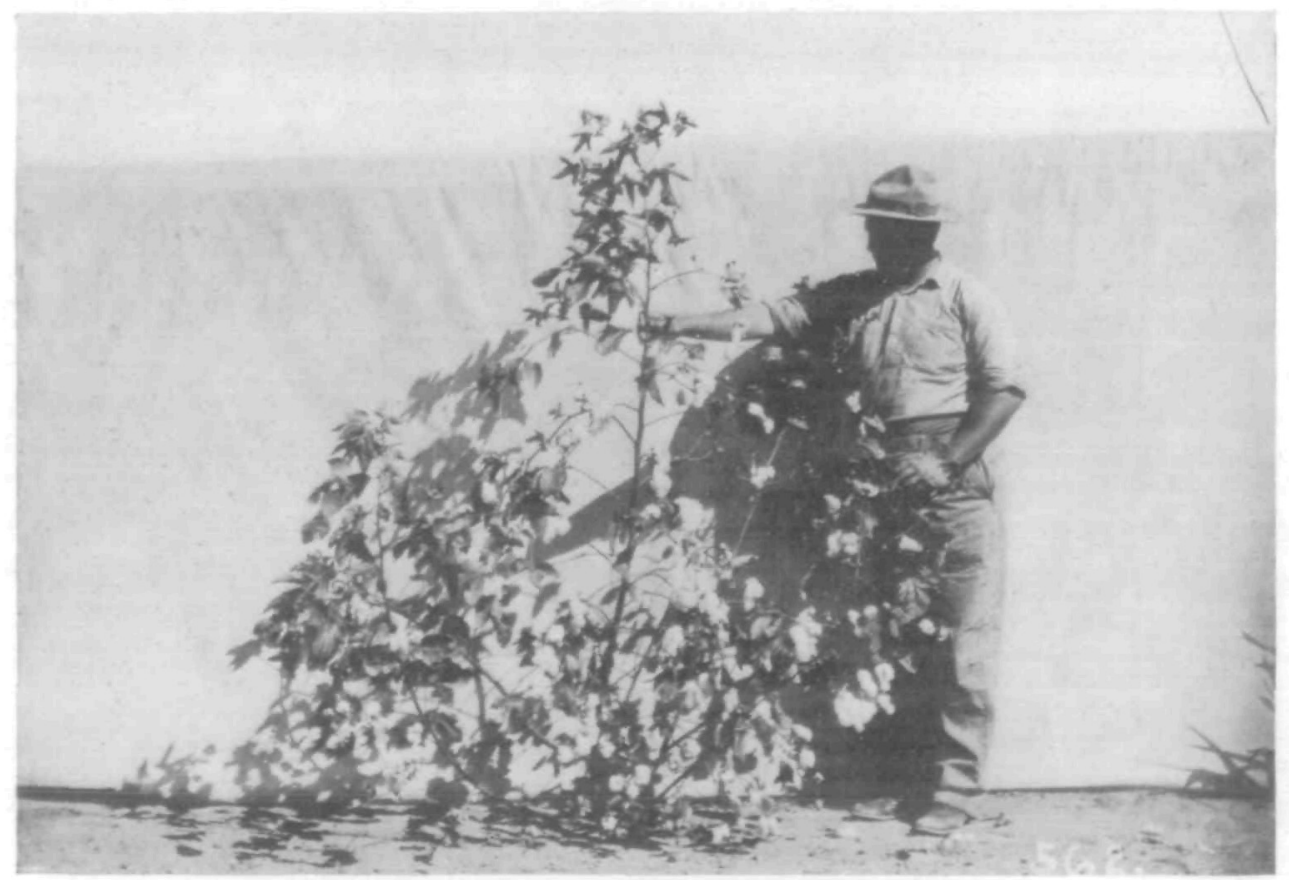

THE RESULT OF SELECTION IN EGYPTIAN COTTON

After several years of selection, a much more productive and earlier strain was developed (Fig. 2). 
inches, hence most Egyptian cotton falls into the long staple class (11/8 inch or longer). The longest Egyptian cotton is surpassed in length only by the best Sea Island.

\section{COTTON CROP OF EGYPT}

The cotton crop of Egypt amounts to 500 or 600 million pounds annually, which is approximately one-tenth of the average production of the United States. The best qualities are grown in the Delta, the cotton of the Nile Valley above Cairo being inferior in the quality and length of the fiber. The crop is grown entirely under irrigation.

Cotton is exported from Egypt to of the principal spinning countries. The United States imported last year about 100 million pounds of this cotton. Egyptian cotton is in great demand for the manufacture of goods requiring a high degree of tensile strength, such as sewing thread, durable hosiery, and automobile tire fabrics.

The Department of Agriculture, about twenty years ago, began experiments to determine whether Egyptian cotton could be grown in the United States. Several introductions were made, the most important by Mr. David Fairchild, who visited Egypt in 1899 and obtained seed of the principal varieties then grown in the country. This seed was tested by Dr. H. J. Webber at a number of stations in the southern and southwestern states. For various reasons it was concluded that commercial production in the main cotton belt would be impracticable, but on the irrigated lands of the southwest the results were so promising as to warrant further experimentation. $^{3}$

\section{SELECTION NECESSARY}

The behavior of the plants grown from imported seed made it evident, however, that selection would be necessary in order to obtain a sufficiently fruitful, early, and uniform stock to justify commercial production. All of the varieties, when first introduced, were not only relatively late ripening and unfruitful (Fig. 1), but were also extremely variable. This lack of uniformity, as was later pointed out by Mr. O. F. Cook, was due to the fact that the conditions under which cotton is grown in Egypt, favor unlimited cross-pollination in the fields and mixing of seed at the gins. ${ }^{4}$ The most serious contamination was due to the abundant presence, as a weed, in Egyptian cotton fields, of the socalled "Hindi." This is a very inferior type, more nearly related to American Upland than to Egyptian cotton, but hybridizing freely with the latter. ${ }^{5}$

EXPERIMENTS BFGUN AT YUMA

Plant breeding experiments were begun by the writer at Yuma, Arizona; in 1903 with Mit Afifi, the variety which at that time was most extensively grown in Egypt. Selection was carried on for several years, resulting in a gradual improvement in the uniformity, earlines and productiveness (Figs. 1 and 2) in the manner in which the bolls opened (Figs. 3 and 4) and in the length of the fiber (Fig. 5). Up to this point, no marked change of type was observed to have taken place.

A new era in the breeding work began in 1908 when two of the progeny rows were found to differ strikingly from the parent stock and from one another. These rows gave rise to the Yuma and Somerton varieties. The latter was soon discarded because of its excessive development of vegetative branches or "limbs," but the Yuma variety was preserved and became the basis of the Egyptian cotton industry in Arizona. This variety differed from the parent Mit Afifi in numerous characters, of which the most conspicuous were the longer and more pointed bolls (Fig. 6) and the longer (about 11/2 inch) and lighter colored fiber (Fig. 5).

A third variety, the Gila, was

3 A year or two prior to the commencement of experiments in the southwest by the Department of Agriculture, Egyptian cotton was grown at Phoenix by the Arizona Agricultural Experiment Station and large yields: were obtained.

4 The Government of Egypt has recently taken measures looking to the maintenance of supplies of pure seed.

${ }_{5}$ Cook, O. F. Hindi Cotton in Egypt. Bureau Plant Industry Bulletin 210 (1911). 


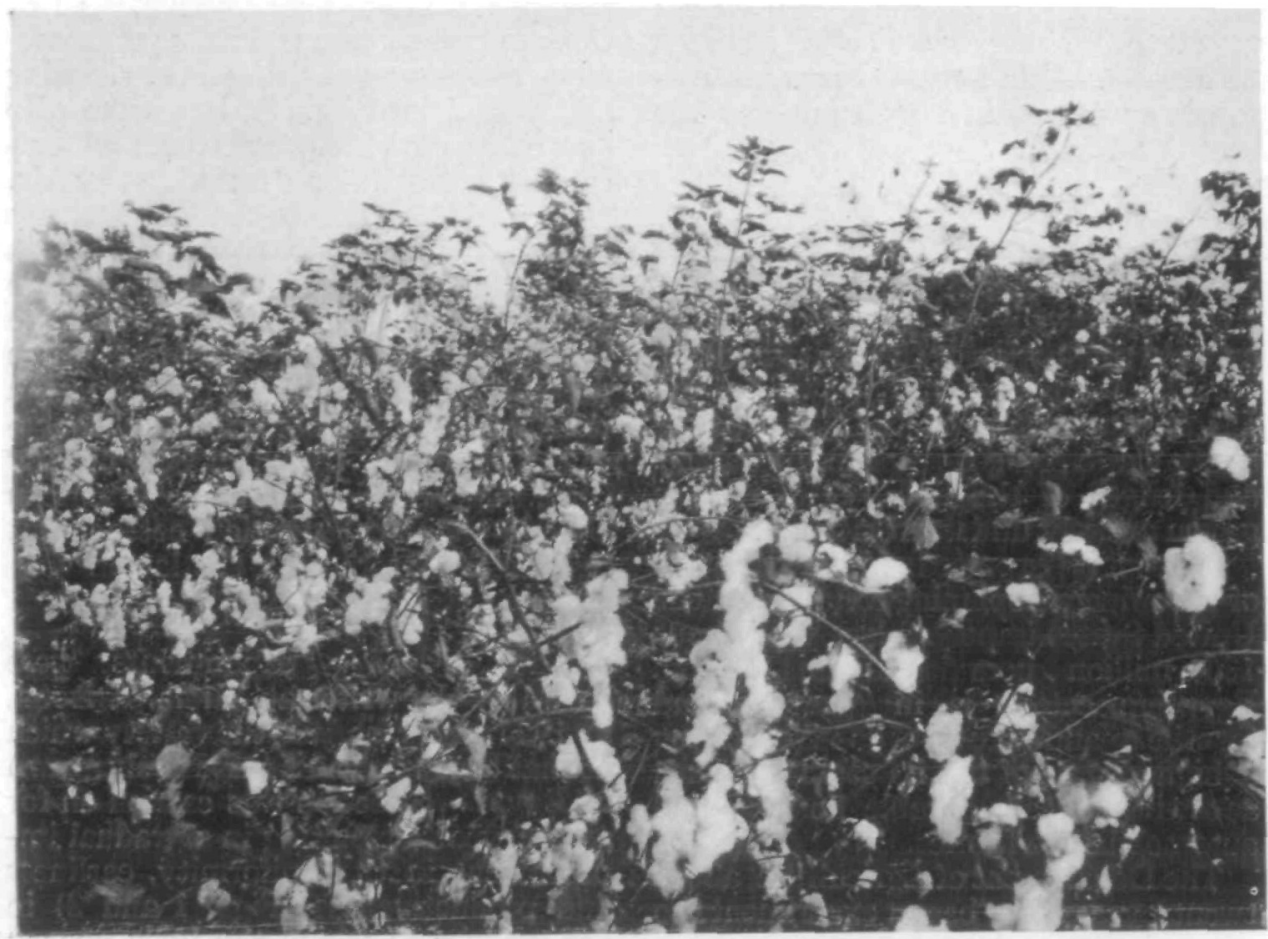

ARIZONA EG YPTIAN COTTON, RESULT OF SELEC'TION

Egyptian cotton grown at Yuma, Arizona, after several years of selection, showing the fruitfulness of the plants and the manner in which the ripe cotton hangs from the bolls, making picking easy. (Fig. 3.)

developed by Mr. E. W. Hudson from a plant selected in 1908 in a field of acclimatized Mit Afifi cotton at Sacaton, Arizona. While less different from Mit Afifi than are the Yuma and Somerton varieties, the Gila seemed to be sufficiently distinct to warrant its recognition as a separate variety.

The three Arizona varieties thus far mentioned were all selected out of Mit Afifi. The Pima variety, on the other hand, was derived from Mit Afifi through Yuma. In 1910, in a field of Yuma cotton at Sacaton, Arizona, a plant was selected because of its superior productiveness and length of fiber.
Upon examination of the remarkably uniform progeny row which was grown the year following from seed produced by this plant; it was at once evident that another new and very distinct variety had appeared. As compared with the parent variety (Yuma), Pima is distinguished by its fewer vegetative branches and better developed fruiting branches (Figs. 7 and 8 ), by its plumper, more sharply pointed and less deeply pitted bolls (Fig. 6), and by its longer (15/8 to $13 / 4$ inch), finer, silkier and lighter colored fiber (Fig. 5). ${ }^{6}$

The commercial production of Egyptian cotton in Arizona began in 1912,7

- For more complete descriptions of the Yuma, Pima and Gila varieties, see Kearney, T. H. Mutation in Egyptian Cotton. Journ. Agr. Res., Vol. ii (1914), pp. 287-302. Pls. 17-25.1

7 Two years previously, when the complexity of the problems involved in the establishment of this new agricultural enterprise had become apparent, the Chief of the Bureau of Plant Industry appointed a Committee on Southwestern Cotton Culture. The original members of this committee were Messrs. O. F. Cook, C. S. Scofield, W. T. Swingle and T. H. Kearney, all of whom had previously collaborated in various phases of the work. Mr. C. J. Brand, Chief of the Bureau of Markets and Rural Organization, and Mr. K. F. Kellerman, Associate Chief of the Bureau of Plant Industry, subsequently became members of the committee. 


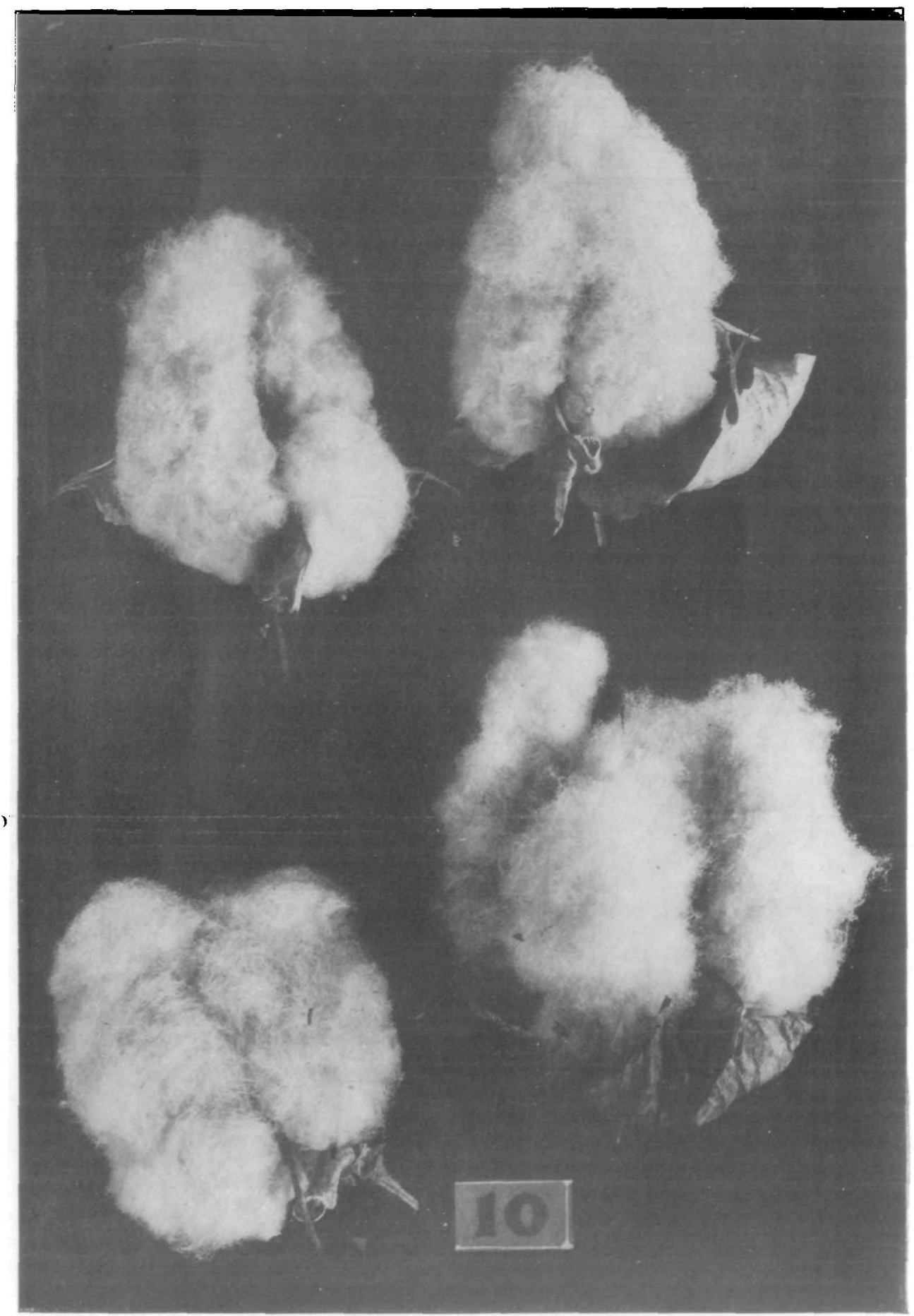

\section{RIPE BOLLS OF THE NEW ARIZONA EGYPTIAN COTTON}

Ripe bolls of Arizona Egyptian cotton after several years of selection. On plants grown from newly imported seed the bolls did not open so fally. Egyptian, like Sea Island cotton, has usually 3-locked bolls, while the bolls of American Upland cotton are usually 4-locked or 5-locked. (Fig. 4.) 


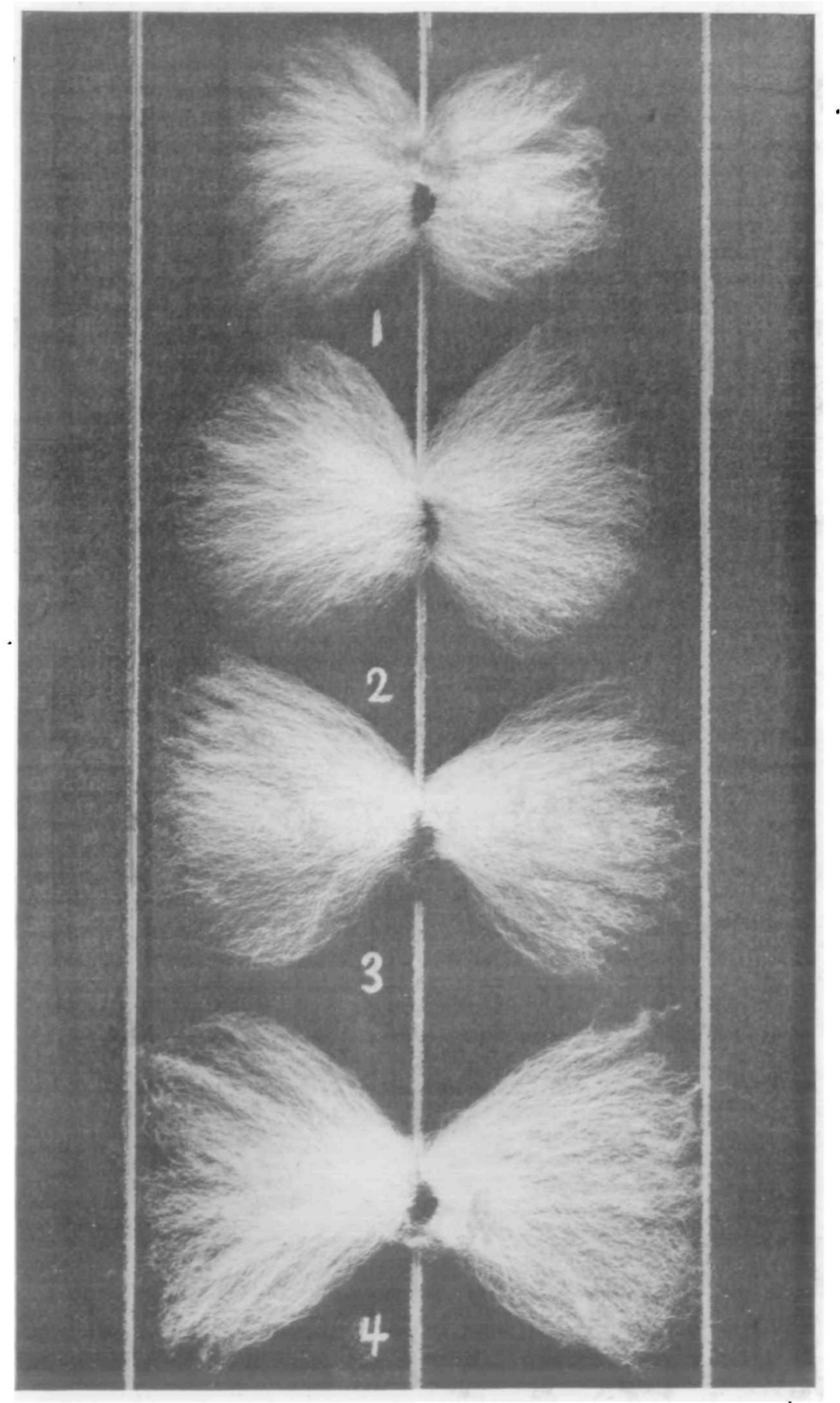

LENGTHENING THE COTTON FIBERS

Egyptian cotton fiber combed out on the seed (slightly reduced from natural size) to illustrate the progress attained by the breeding work in Arizona. The specimens are as follows: (1) From a first selection in the original stock of Mit Afifi; (2) from a strain of Mit Afif after three years of selection; (3) from the parent plant of the Yuma variety; (4) from a plant of the Pima variety. (Fig. 5.) 

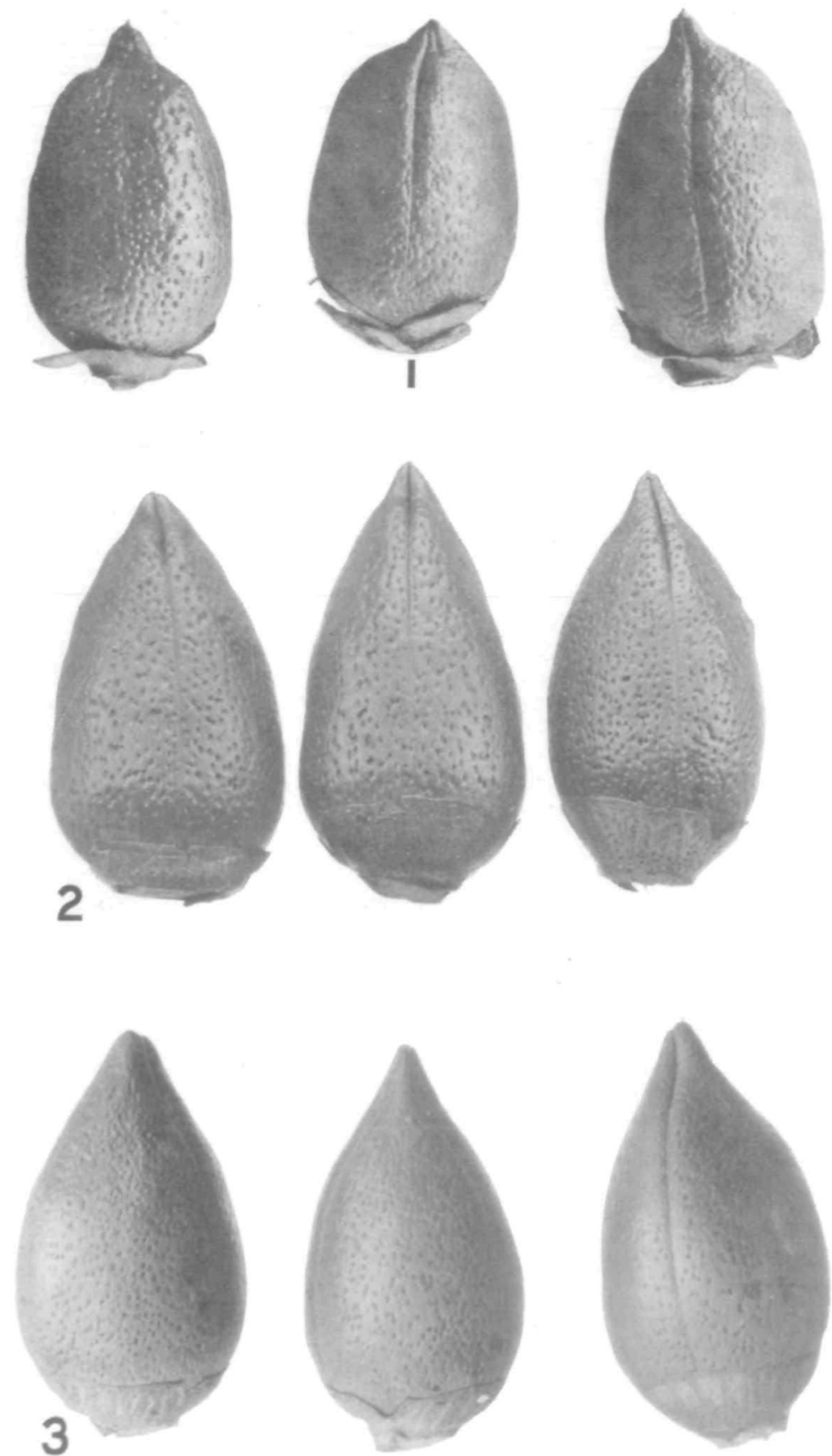

UNOPENED BOLLS OF EGYPTIAN COTTON

Showing the differences in shape and in the character of the surface which distinguish the varieties. (1) Mit Affi; (2) Yuma; (3) Pima. (Fig. 6.) 


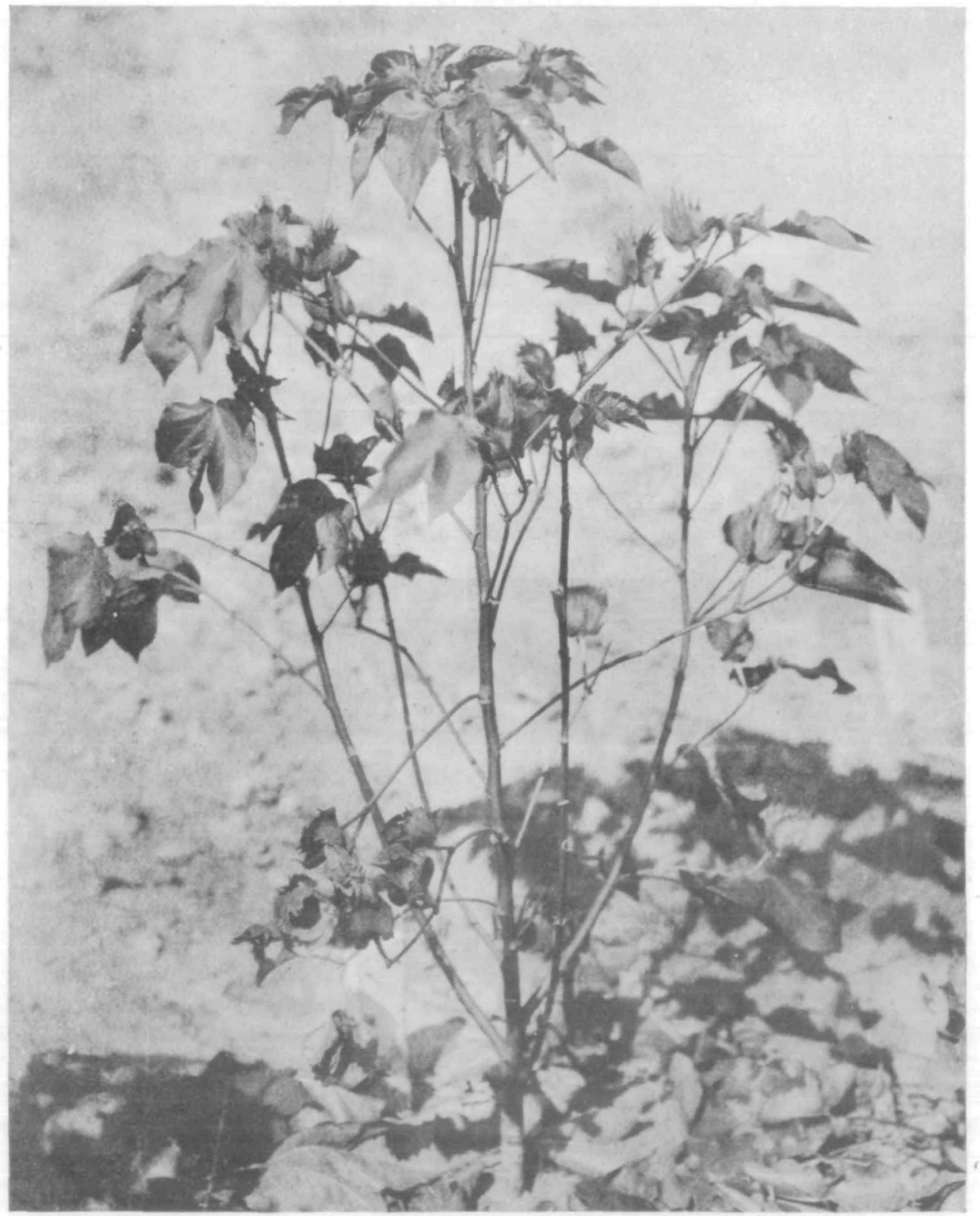

AN UNDESIRABLE BRANCHING HABIT

A half-grown plant of the Yuma variety with the leaves removed to show the branching habit. The Yuma variety has several large vegetative branches or "limbs" and its lower fruiting branches are often poorly developed. Photograph by C. B. Doyle. (Fig. 7.) 


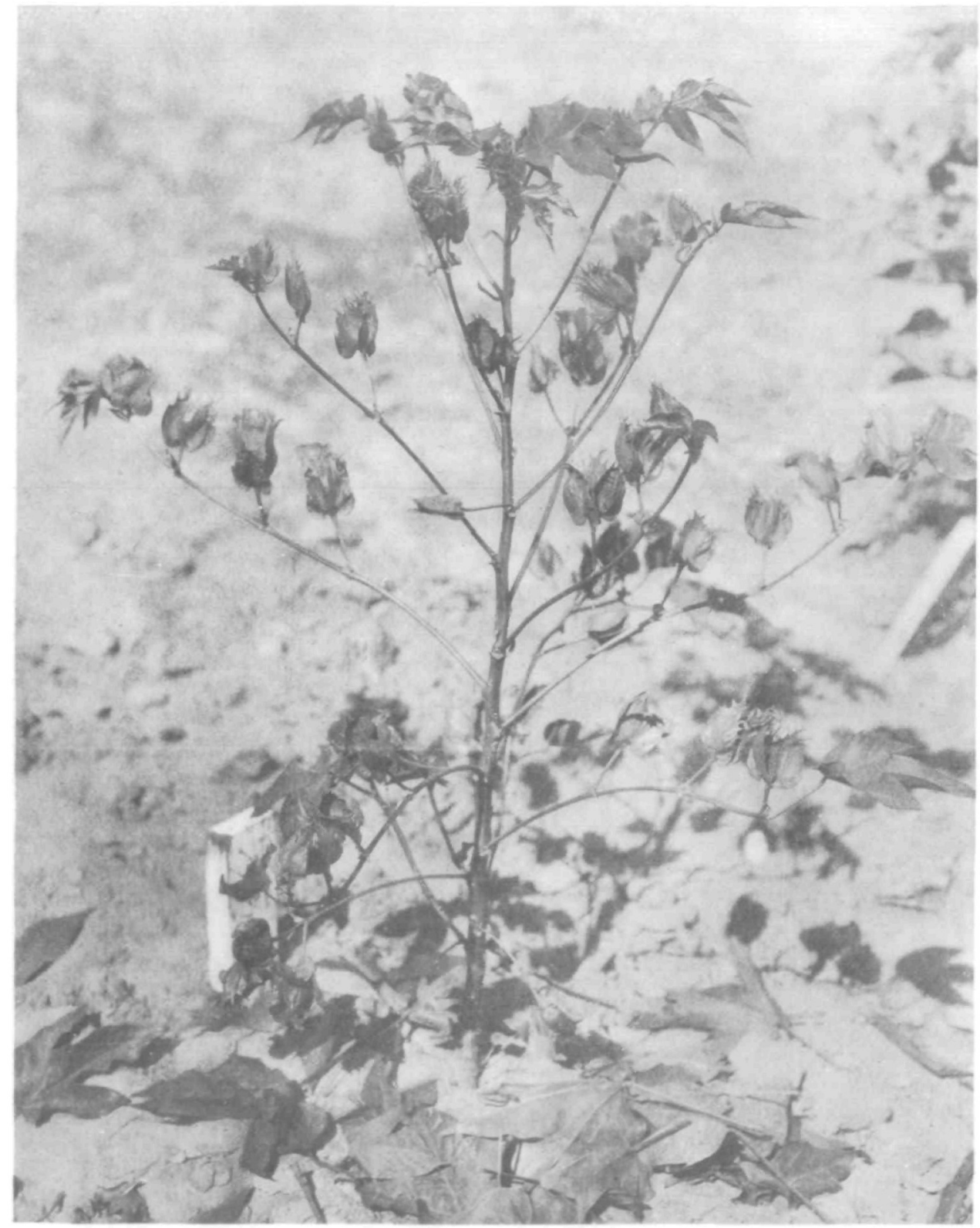

PIMA COTTON PLANT WITH PRODUCTIVE BRANCHING HABIT

The Pima variety differs from the Yuma variety, of which a plant of the same age as this one is shown in Fig. 7 , in being often limbless and in having its lower fruiting branches well furnished w:th bolls. Photograph by C. B. Doyle. (Fig. 8.) 
when the Department of Agriculture supplied seed of the Yuma variety to farmers in the Salt River Valley and some 200 acres were planted. From this small beginning the industry expanded until in 1917, in the Salt River Valley alone, about 23,000 acres of Yuma cotton and about 7,000 acres of Pima cotton were grown and the value to the farmers of the fiber and seed produced was estimated atabout $\$ 5,000,000$ (Frontispiece). The prospects are that in 1918 not less than 100,000 acres will be planted to this crop. ${ }^{8}$

The fiber of both the Yuma and Pima varieties has found much favor with American spinners, the automobile tire manufacturers having shown especial interest in this product. The Pima variety, being preferred because of its earliness and its longer fiber, will probably soon completely replace the Yuma.

\section{HOW TO MAINTAIN UNIFORMITY}

Although the Yuma variety was very uniform at the outset, as now commercially grown in Arizona it comprises numerous forms which differ markedly from the original type and which "come true" when self-pollinated. This diversity is undoubtedly due to the fact that the original progeny row was not protected from cross pollination with other types. The seed which was subsequently supplied to farmers for commercial planting was the increase from this row, and although the markedly off type plants had been "rogued" from the seed increase fields, the stock was by no means as pure as several generations of line- breeding would have made it. 'Subsequent experience has shown that a high degree of uniformity can be maintained in the Yuma variety when the latter method is followed.

The Pima variety, having been strictly line-bred and having been kept effectively isolated, has remained uniform. Proof of this was obtained in roguing the seed increase fields during the past three seasons. Although more than two million plants were examined, not a single variant was detected which could be compared, in the magnitude of its departure from the type, with the parent plants of the Yuma and Pima varieties.

\section{FARMERS COÖPERATING}

A coöperative association of cotton growers in the Salt River Valley, assisted by the Department of Agriculture, is strenuously endeavoring to maintain the purity of the Pima variety by isolation of the seed increase fields and by separate ginning. Since it has never been proven that a stock of cotton. if free from hybrids at the outset, will "run out" white as it is protected from crossing with other sorts, there is good reason to expect that deterioration of this valuable variety can be indefinitely postponed.

\section{ORIGIN BY MUTATION}

The mutational origin of the four varieties of Egyptian cotton which have been developed in Arizona is indicated by the following facts. Each variety was derived from a single plant which appeared suddenly and differed conspicuously in several characters from the parent stock. Intermediate forms were not observed. The progenies of these plants remained uniform in their expression of the new characters, so long as cross-pollination with other forms was prevented.

Origin by mutation seems also to be fairly well established in the case of the numerous varieties which have arisen from time to time in Egypt, although the records are less complete than those of the Arizona varieties. Four varieties of comparatively recent origin, Abbassi, Yannovitch, Nubari, and Sakellaridis, are each reported to have been derived from a single plant selection in a field of Mit Afifi. All of these varieties appear to have been relatively uniform when first grown, but have rapidly deteriorated through, cross pollination

${ }^{8}$ For a more complete account of the development of the Egyptian cotton industry in Arizona the reader is referred to U. S. Department of Agriculture Bulletin 332 (1916), entitied Community Production of Egyptian Cotton in the United States. 
and seed mixture. Consequently the maintenance of the Egyptian type of cotton has until recently depended upon the successive appearance of desirable mutants which have given rise to new varieties.

It is a noteworthy fact that mutation in Egyptian cotton is associated with lack of purity in the parent stock. From the Mit Afifi, which, like all varieties grown in Egypt, has become a congeries of biotypes, the parents of several wellmarked varieties have been selected in Egypt and in Arizona. Similarly the Yuma variety offers numerous heritable variations and has given rise to one very distinct new variety, the Pima. On the other hand in the Pima variety, which has been protected from crosspollination with other stocks, no conspicuous mutant has yet been detected. Nor have mutants been found in such stocks of the Yuma, Gila and Sakellarides varieties as have been line-bred.

While mutation in Egyptian cotton has been observed only in heterozygous stocks, the origin of such extreme mu- tants as Yuma and Pima can scarcely be explained by the recombination hypothesis. Comparison of the parent stock with any other with which it could have had recent opportunity to hybridize did not reveal the source of the distinguishing characters of the mutant. Furthermore, the absence or extreme rarity of forms intermediate between parental type and mutant does not accord with the current conception of recombination.

It will be asked whether the origin of varieties in other types of cotton is likewise due to mutation. How, for example, have the almost innumerable varieties of American Upland cotton come into existence? The data at hand do not allow of a positive answer to this question, although it seems to be fairly well established that many of the Upland varieties have been derived from single-plant selections. The presumption that these plants were mutants is not a far-fetched one, since it would seem improbable that Egyptian is the only type of cotton which is in a mutating condition.

\section{Why the Button-Ball Degenerates in Towns}

To the Editor of Journal of Heredity:

I have followed with much interest your articles on Platanus. I am tempted to write this letter by a question in your issue of December, 1917, page 553.

Prof. Augustine Henry, Royal College of Science for Ireland, Dublin, asks:

"Can anyone explain how the native species of Platanus is inferior to the imported one, and why the latter is preferred: How the former degenerates when planted in American towns?"'

The native species, Platanus occidentalis, requires a rich, deep and somewhat sandy soil in which it grows to great size. I have seen trees from 4 to 5 feet in diameter growing along the streams in eastern Kansas. Some that were reduced to saw logs proved to be sound to the core. When planted on the heavy soil of uplands, or in towns where stones, brick-bats, ashes and other similar material are mixed with the already poor soil, the species has a very hard time of it and is generally sickly and short-lived.

Platanus orientalis is naturally more vigorous and of quicker growth; it does not object to the heavy soils, excepting when there is too much alkali present.

This has been my experience during many years of close observation.

Yours very sincerely,

$$
\begin{gathered}
\text { E. F. A. REINisCH, } \\
\text { Supt. of Parks, } \\
\text { Topeka, Kans. }
\end{gathered}
$$

